\section{The First Enantioselective Rhodium-Catalyzed 1,4-Addition}
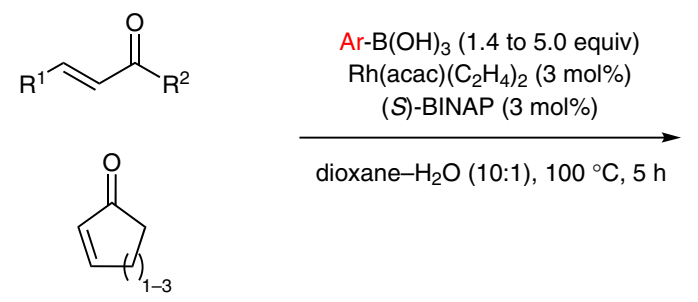

\section{Key words}

rhodium catalysis

1,4-addition

asymmetric arylation

Selected examples:

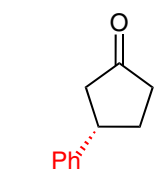

$93 \%$ yield, $97 \%$ ee

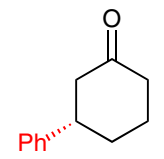

$99 \%$ yield, $97 \%$ ee
12 examples

up to $99 \%$ yield

up to $99 \%$ ee<smiles>CC(=O)C[C@H](c1ccccc1)C(C)C</smiles>

$82 \%$ yield, $97 \%$ ee<smiles>O=C1CCC[C@H](c2ccc(C(F)(F)F)cc2)C1</smiles>

$70 \%$ yield, $99 \%$ ee<smiles>CC(=O)CC([18OH])[13CH]C(C)=O</smiles>

$88 \%$ yield, $92 \%$ ee<smiles>O=C1CCC[C@H](c2cccc(Cl)c2)C1</smiles>

$94 \%$ yield, $96 \%$ ee<smiles>CC(C)(C)C=C[C@H]1CCCC(=O)C1</smiles>

$76 \%$ yield, $91 \%$ ee
Significance: Although Miyaura was the first to report rhodium-catalyzed conjugate addition of boronic acid reagents (M. Sakai, H. Hayashi, N. Miyaura Organometallics 1997, 16, 4229), it was the combined effort of Hayashi and Miyaura that, in the present work, demonstrated that this process can be done with a high level of enantioselectivity. This reaction, now often referred to as the HayashiMiyaura reaction, has become highly popular because: 1 ) it proceeds under neutral reaction conditions, 2) no background uncatalyzed 1,4-addition occurs, 3) no 1,2-addition in the presence or absence of catalyst takes place, and 4) it has a high functional group tolerance.
Comment: The authors noted that the reaction works best with $\left[\mathrm{Rh}(\mathrm{acac})\left(\mathrm{C}_{2} \mathrm{H}_{4}\right)_{2}\right]$ as opposed to the racemic version, which proceeded with $\left[\mathrm{Rh}(\mathrm{acac})(\mathrm{CO})_{2}\right]$. The ethylene complex enables facile formation of the active [Rh(acac)(BINAP)] species. Another modification from the original work is the higher reaction temperature. This work represented the first time that high yields and enantioselectivities could be achieved in an aryl group 1,4addition using a chiral BINAP ligand. Since this seminal report, other ligand classes have been elucidated, and this venerable methodology has been expanded to include domino reaction systems. 